\title{
Open Stented Grafts for Frozen Elephant Trunk Technique: Technical Aspects and Current Outcomes
}

\author{
Wei-Guo Ma, MD ${ }^{1,2}$, Jun Zheng, MD', Li-Zhong Sun, MD ${ }^{1 *}$, John A. Elefteriades, MD² \\ ${ }^{1}$ Department of Cardiovascular Surgery, Beijing Anzhen Hospital, Capital Medical University, Beijing Institute of Heart, Lung and \\ Blood Vessel Diseases, and Beijing Engineering Research Center of Vascular Prostheses, Beijing, China \\ ${ }^{2}$ Aortic Institute at Yale-New Haven, Yale University School of Medicine, New Haven, Connecticut, USA
}

\begin{abstract}
With growing experience in patients with aneurysms and dissections in the arch and proximal descending aorta, the frozen elephant trunk (FET) technique has been shown to be safe and effective, and has achieved favorable short to mid-term outcomes. As the FET technique is gaining wider acceptance, there is a growing need for versatile, technically simple, and highly durable open stented grafts involving less complicated deployment mechanisms enabling use in various indications. This paper gives a brief review on the technical aspects and clinical outcomes of currently available open stented grafts used in the FET technique, including the E-vita Open Plus, Thoraflex Hybrid, Cronus, and $J$ Graft. While none of these grafts can claim to be an ideal device, technology continues to improve towards this goal. As newer devices and systems are developed, more widespread use of the FET technique can be expected; such progress promises to improve the clinical outcomes and quality of life for patients with complex aortic diseases.
\end{abstract}

Copyright $\odot 2015$ Science International Corp.

\section{Key Words}

Aorta - Blood vessel prosthesis implantation • Frozen elephant trunk • Surgery • Stents - Aneurysm • Aortic dissection

Diseases of the aortic arch and descending aorta remain among the great challenges in cardiovascular

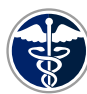

Fax +1 2037853552

E-Mail: aorta@scienceinternational.org

http://aorta.scienceinternational.org (c) 2015 AORTA

Published by Science International Corp. ISSN 2325-4637

Accessible online at:

http://aorta.scienceinternational.org surgery. In March 1982, Dr. Hans-Georg Borst introduced the 2-stage elephant trunk technique in Hannover, Germany, which has greatly facilitated surgical treatment of this special pathologic entity [1]. Nevertheless, the cumulative risks of two major surgical procedures [2-4] stimulated further explorations aimed at achieving complete repair of extensive aortic lesions in one single operation $[5,6]$. As the first inhuman application of intraluminal stent graft for aortic aneurysms by Juan Parodi had fueled subsequent innovations [7], Dr. Kato proposed a modification to the classic elephant trunk technique [8] based on his early investigations [9-11], in which a covered endovascular stent graft is deployed into the descending aorta through the open aortic arch. The open stented graft (OSG) can be securely fixed at the desired level inside the distal descending aorta, allowing thrombus formation within the space between the graft and the aortic wall. The inventor of the elephant trunk technique, Hans-Georg Borst, named this approach the "frozen elephant trunk (FET)" [12], which has been increasing steadily in use since the late 1990s [13-16].

With growing experience in patients with aneurysms and dissections of the arch and proximal descending aorta, the FET technique has been shown to be safe and effective, with favorable early and long-term outcomes [16-24]. Accordingly, the FET technique is gaining wider acceptance among the cardiovascular surgical community, resulting

\footnotetext{
* Corresponding Author:

Li-Zhong Sun, MD

Department of Cardiovascular Surgery

Beijing Anzhen Hospital, Beijing Aortic Disease Center, Capital Medical University

2 Anzhen Road, Beijing 100029, China

Tel. +86 106445 6168, Fax: +86 106445 6168, E-Mail: lizhongsun@outlook.com
} 


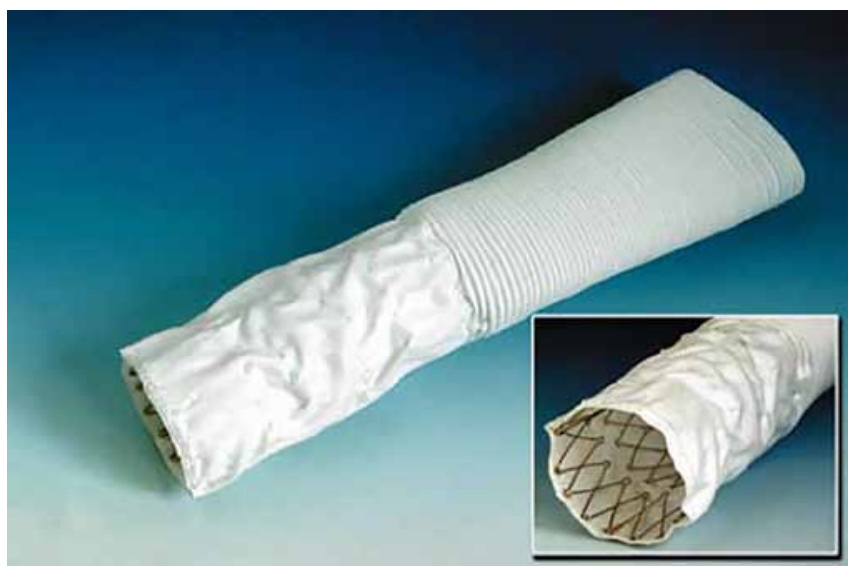

Figure 1. The Chavan-Haverich endograft [27] (Reprinted with permission from Springer).

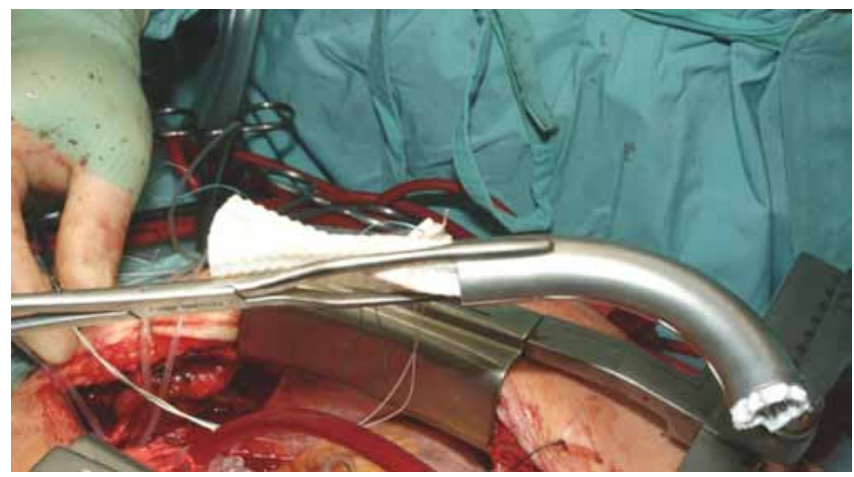

Figure 2. Delivery of the Chavan-Haverich endograft (Courtesy of Dr. Maximilian Pichlmaier).

in a growing need for open stent grafts. This paper aims to review briefly the currently available OSGs used in the FET technique, including the E-vita Open and Open Plus, Thoraflex Hybrid, Cronus, and J Graft open stent graft, with emphasis upon technical aspects and clinical outcomes.

\section{Chavan-Haverich Prosthesis (Non-Commercial)}

Designed by Drs. Chavan and Haverich again in Hannover, the custom-made endograft (Curative $\mathrm{GmbH}$, Dresden, Germany) was the prosthesis for FET in the Hannover group before 2007 [25, 26]. It is composed of a proximal unstented Dacron tube and a distal stented tube with Z-shaped stainless steel stents affixed to the inner aspect (Figure 1) [27]. A 5-mm gap between the stents, maintained by two longitudinally oriented stainless steel wires, allows for flexibility of the graft. The stents are $30-46 \mathrm{~mm}$ in diameter and individually $22 \mathrm{~mm}$ in length. There may be three or four stents, depending on individual patient's size and anatomy.

The delivery system consists of a 39 French (F) outer sheath, a $34 \mathrm{~F}$ inner sheath and a central pusher $[12,28-31]$. It is introduced in an antegrade fashion into the descending aorta via a guide wire which is inserted transfemorally. Positioning may be determined with a C-arm or by measurements on preoperative CT scan. The outer sheath is withdrawn while the inner sheath and the pusher are held steady, and the stented portion will be deployed in the descending aorta. The proximal Dacron graft is released by pulling back both sheaths simultaneously while holding the pusher steady. Then the delivery system is extracted completely. The proximal unstented part is sutured circumferentially to the aorta distal to the origin of the left subclavian artery with 3-0 running polypropylene. The arch branches are anastomosed end-to-side to the Dacron graft as a Carrel patch [28-31]. The initial tube graft was unsealed and bleeding was a serious issue. The sealant used in the later version reduced bleeding considerably, however the release of the graft from the delivery system became a problem due to adhesions. Hereafter, while further development was underway, the prosthesis was thus compressed and delivered with a special clamp shaped like a curved tube in two halves (Figure 2). Because the stented part is stiff and the clamp is $28 \mathrm{~mm}$ in diameter, it is difficult to implant especially in cases of acute Type A dissections and small descending aortas.

In a report by the Hannover group, the Chavan-Haverich prosthesis was implanted in 65 patients (17 acute dissection, 29 chronic dissection and 19 aneurysm) with a mean age of $61 \pm 13$ years. The times of cardiopulmonary bypass and selective antegrade cerebral perfusion were $227 \pm 63$ and $64 \pm 20$ minutes, respectively. Early deaths occurred in 6 (9\%), stroke in 5 (8\%), and spinal cord injury in 1 (2\%). Distal reintervention was required in 22 cases (33\%) and freedom from late distal operation was $83 \pm 5 \%, 74$ $\pm 6 \%$, and $47 \pm 14 \%$ at 1,5 , and 10 years, respectively. Late death occurred in 11 patients (18\%) and the overall survival was $88 \pm 4 \%, 72 \pm 6 \%$, and $62 \pm 9 \%$ at 1,5 , and 10 years, respectively [25]. 


\section{E-vita Open and E-vita Open Plus}

The $\mathrm{E}^{\oplus}$-vita Open Plus hybrid prosthesis is an updated version of its predecessor, E-vita Open (Jotec $\mathrm{GmBH}$, Hechingen, Germany). Invented by Dr. Jakob [32], these grafts are similar in design, but the updated version is less blood permeable and obviates the need for pre-sealing with fibrin glue. The E-vita Open Plus is fabricated from a specially texturized polyester yarn and has a water permeability index of $60 \mathrm{~mL} /$ $\mathrm{min} / \mathrm{cm}^{2}$ in contrast to $650 \mathrm{~mL} / \mathrm{min} / \mathrm{cm}^{2}$ of the E-vita Open [33].

The hybrid prosthesis consists of a stented portion with a flexible, Z-shaped nitinol wire $(13$ to $16 \mathrm{~cm}$ long, 24 to $40 \mathrm{~mm}$ in diameter) covered by a polyester fabric. A proximal nonstented woven graft ( 5 or $7-\mathrm{cm}$ long) is fixed circumferentially to the proximal end of the stented portion. The proximal and distal grafts are identical in diameter, and a sewing collar is added between them in the latest design to facilitate anastomosis (Figure 3) [34], which is similar to the Vascutek Hybrid. Radiopaque markers are integrated in the graft to permit radiological imaging.

The delivery system consists of a shaft, a grip handle, catheters, a release switch, and a positioning aid. The delivery system is over $100 \mathrm{~cm}$ in length and suitable for patients with large statures. The whole prosthesis is placed over a stiff guide wire inserted transfemorally and deployed with a "squeeze-torelease" mechanism, in which the prosthesis will be introduced $4 \mathrm{~mm}$ forward into the proximal descending aorta by every "squeeze" of the lever (Figure 3 ). The deployment of the stented graft is achieved by

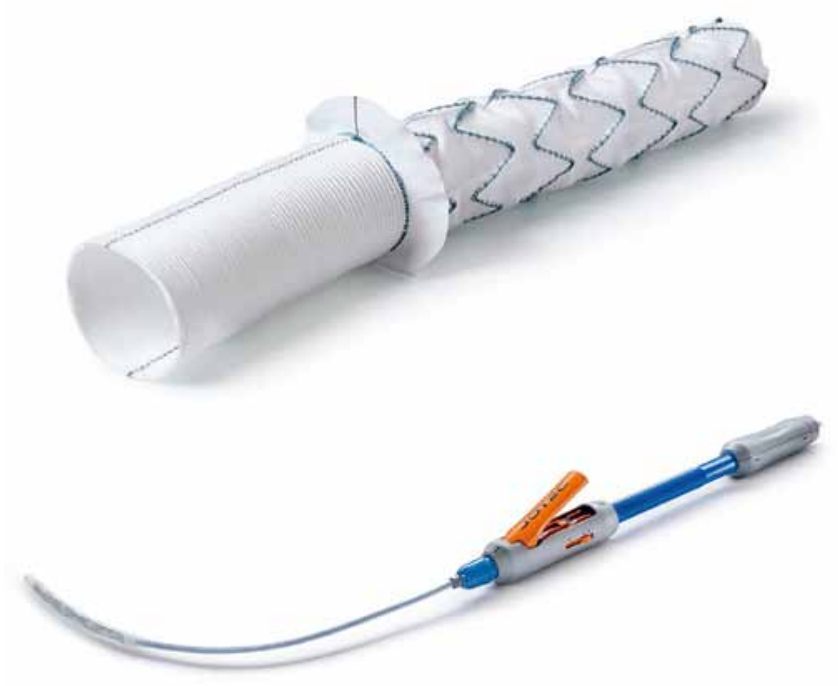

Figure 3. The E-vita Open Plus hybrid prosthesis and its delivery system [30] (Adapted with permission from Jotec $\mathrm{GmbH}$ ).

the retraction of the retaining sheath (see supplemental Video 1 at http://dx.doi.org/10.12945/j.aorta. 2015.14.062.vid.01) [35]. The invaginated unstented graft is then pulled back. Distal anastomosis at a level between the left subclavian artery and proximal descending aorta is completed with continuous stitches of 3-0 polypropylene secured with an external Teflon felt strip [35]. The arch branches are reattached endto-side to the proximal graft using the 3-vessel Carrel patch technique (Figure 4) [36].

In retraction of the stented graft, the prosthesis may slide within the aortic lumen, which complicates

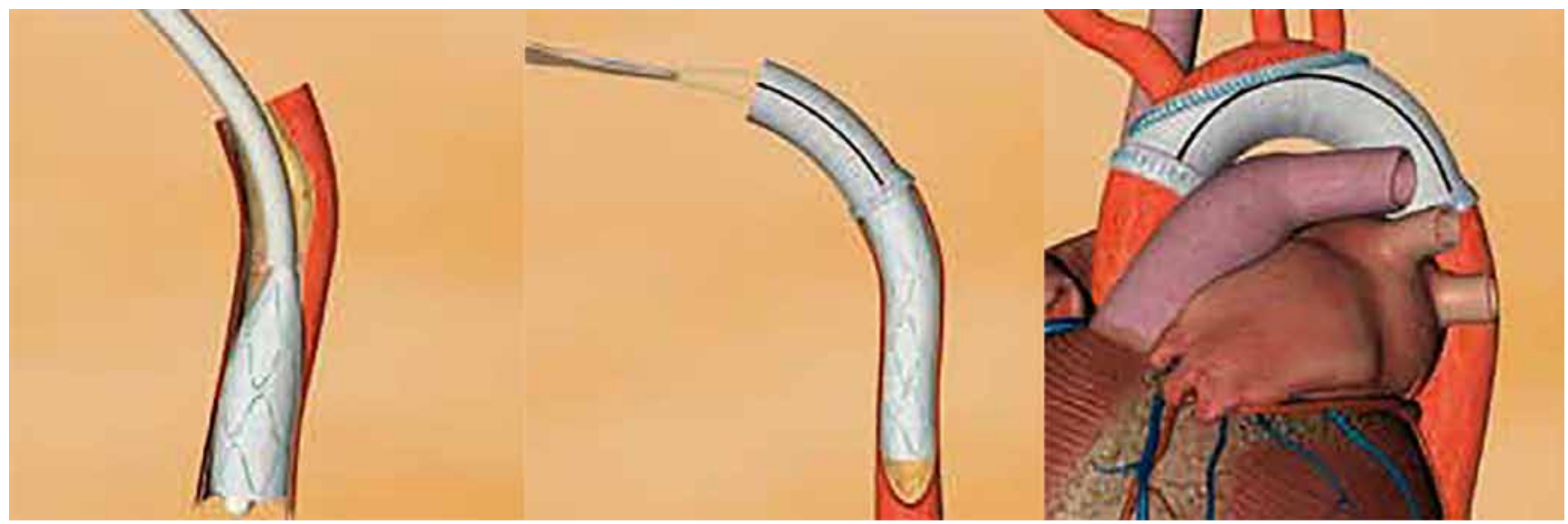

Figure 4. Deployment of E-vita Open Plus and reconstruction of the aortic arch [32] (Adapted with permission from Jotec GmbH). 
proper positioning. Difficulties during extraction of the delivery system were also reported in early series [37]. In the latest version, the previous design of solid ballpoint tip is replaced by a balloon tip, which facilitates deployment and reduces injury to the aortic intima [34].

The E-vita Open entered the European market in 2005 and was replaced by E-vita Open Plus, which received a CE mark in June 2014. By December 2015, over 5000 patients were successfully treated [34]. The International E-vita Open registry, which was launched in 2005 [38-40], has recruited 575 patients from 10 European centers by August 2014 [41]. Postoperative data was complete in 568 patients, including 211 (37.1\%) acute dissections, 187 (32.9\%) chronic dissections, and 170 (29.9\%) aortic aneurysms, with a mean age of 59, 58, and 67 years, respectively. The times of cardiopulmonary bypass, cross-clamp, and selective antegrade cerebral perfusion were 245, 252, and 220 minutes, 144, 148, and 124 minutes and 66,88 , and 66 minutes, respectively. In-hospital mortality was $18 \%, 17 \%$, and $12 \%$ for each group; permanent stroke occurred in $6 \%, 1 \%$, and 0 ; spinal cord injury occurred in 3\%,4\%, and 4\%, and dialysis in $2 \%, 5 \%$, and $4 \%$, respectively. Follow-up was completed in $91 \%$ (517/568). CT scan was performed in 141,87 , and 89 patients in each group, respectively. At the latest follow-up, complete thrombosis of false lumen was seen in $94 \%$ and $86 \%$ in patients with acute and chronic dissections, and complete exclusion in $94 \%$ of aneurysm patients at the stent graft level. At 5 years, survival was $85 \%, 79 \%$, and $69 \%$ for acute dissection, chronic dissection, and aneurysmal patients. Freedom from endovascular repair was $95 \%$, $73 \%$, and $87 \%$, and freedom from open repair on the downstream aorta was 98\%, 91\%, and 95\%, respectively [41].

\section{Thoraflex Hybrid}

Designed by Drs. Haverich, Shrestha, and Pichlmaier, the Thoraflex ${ }^{\mathrm{TM}}$ Hybrid prosthesis (Vascutek, Inchinnan, Scotland, UK) consists of a proximal unstented sealed woven Dacron tube and a distal stented part made of polyester and nitinol stents. The unstented portion has four integrated side branches: three for arch vessel reconstruction and one for distal and antegrade cerebral perfusion. The stented part is 10 or $15 \mathrm{~cm}$ in length and $28-40 \mathrm{~mm}$ in diameter (Figure 5). The proximal unstented and distal stented segments of the graft are different in diameter. The unstented part is smaller, which allows for space in the arch for branch reconstruction. There is a sewing collar between the proximal and distal segments, which facilitates suturing of the distal anastomosis, especially in patients with aneurysm of the arch and proximal descending aorta (Figure 6). The design with independent, ring-shaped stents not only allows for better arch curvature and anatomic conformity to the descending aorta but also reduces the radial force on the aortic wall, thus minimizing the risk of intimal injury in patients with aortic dissection. Radiopaque markers are incorporated in

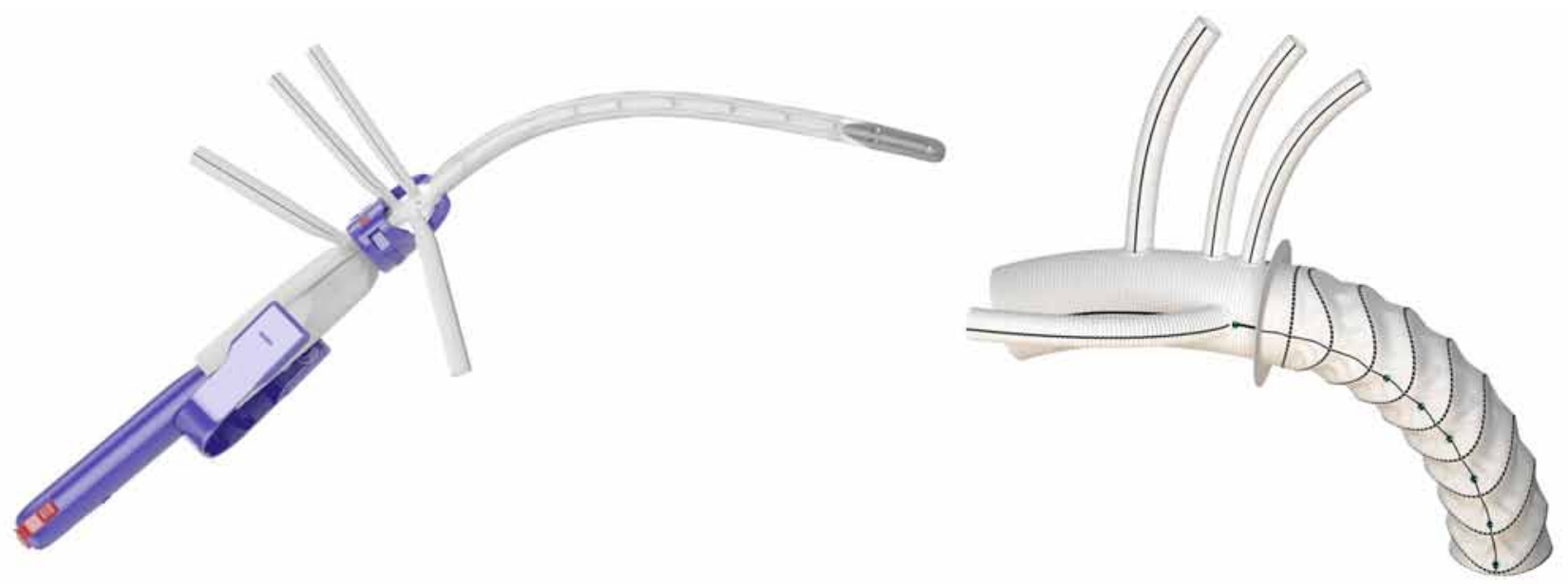

Figure 5. The Thoraflex Hybrid prosthesis and its delivery system (Courtesy of Vascutek, Terumo Cardiovascular Systems, adapted with permission). 


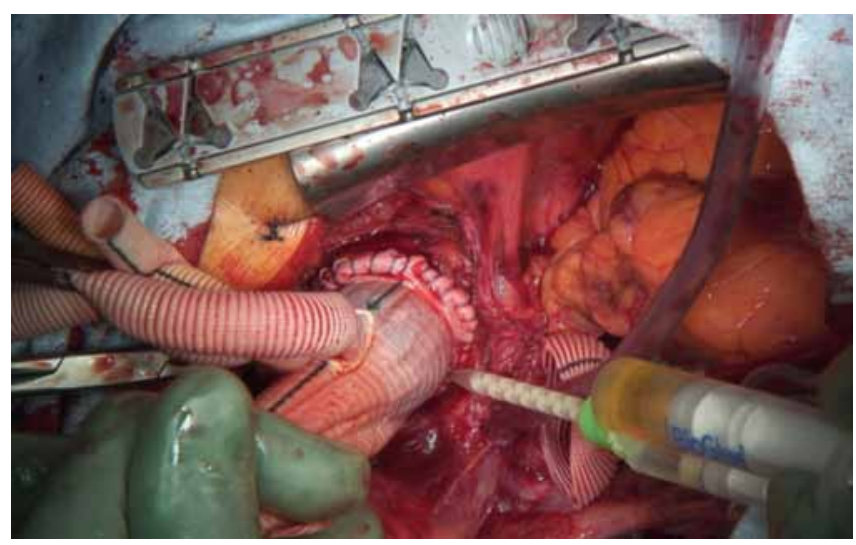

Figure 6. Operative view of the sewing collar of Thoraflex ${ }^{\text {TM }}$ Hybrid after completion of distal anastomosis (Courtesy of Dr. Maximilian Pichlmaier).

both the proximal graft and the distal stented portion for radiological visualization. The prosthesis is impregnated with bovine gelatin, which eliminates the need for pre-clotting [42].

The delivery system consists of a central catheter, a malleable stainless steel shaft with outer PTFE splittable sheath, and a handle that is made from a range of molded thermoplastic polyurethane. The stented portion is first bent slightly to fit the curvature of the descending aorta, and may then be advanced down over a stiff guide wire by a side rail technique. The sheath is bisected by pulling it through the splitter using the strap thereby enabling the stent to open. The splitter is then removed to free the sewing collar. Before the delivery system can be removed from the hybrid graft, the tip capture mechanism for placement correction has to be released by pulling the release wire clip at the back of the handle (see supplemental Video 2 at http://dx.doi.org/10.12945/j. aorta.2015.14.062.vid.02). The distal anastomosis is performed with the sewing collar using a 3-0 running polypropylene and may be reinforced with a second layer of pledgeted 3-0 polypropylene. The fourth side branch is cannulated to reperfuse the lower body. The arch vessels are reconnected to the side branches of the proximal unstented graft in an end-to-end fashion (Figure 7), occasionally using bridging stents, Viabahn $^{\circledast}$ (W. L. Gore \& Associates, Newark, DE) [43].
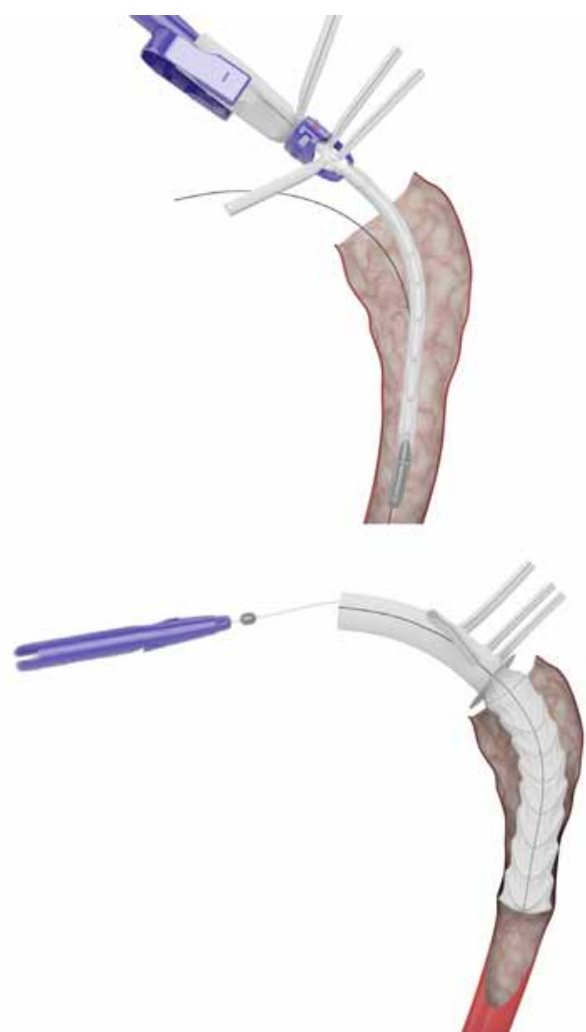
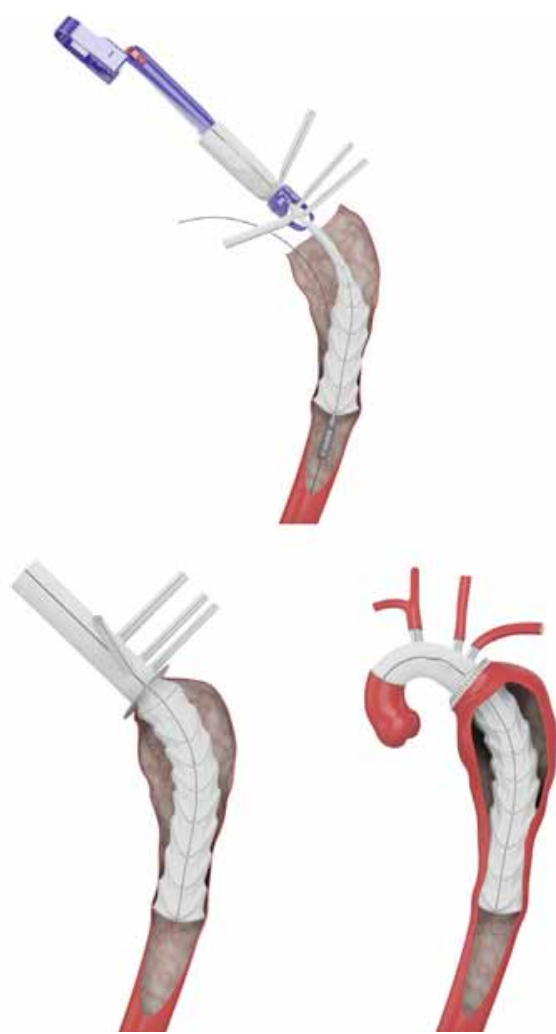

Figure 7. Deployment of Thoraflex Hybrid prosthesis and arch reconstruction (Courtesy of Vascutek, Terumo Cardiovascular Systems, adapted with permission). 
The integrated side branches represent a unique and highly valuable feature that allows for separate reconstruction of the arch vessels [44], which may be important in patients with a severely atherosclerotic aortic arch, Marfan syndrome and considerable distance between the origins of the arch vessels. Compared to other straight grafts, the 4-branched graft may reduce the time of lower body and myocardial ischemia, which is generally associated with improved outcomes after complex aortic arch reconstruction [45]. A concern may arise after the anastomosis of the sewing collar to the proximal descending aorta is completed and the graft and side branches are fixed in position [46]. Although the side branches can be cut to desired lengths before anastomosing to the arch vessels to avoid kinking and twisting, at this stage it is difficult to rotate the side branches along the long axis of the aorta, should this be required [37]. Manual deployment of Thorflex hybrid may also be hindered by the four arch branches in the operative field [47]. Its use may also be limited by the aortic anatomy in chronic arch pathologies [48].

The Thoraflex ${ }^{\mathrm{TM}}$ Hybrid received CE mark in November 2012 and there were more than $1180 \mathrm{im}$ plants by December 2015 [Mr. Jonathan Hargreaves, Personal communication (email), January 2016]. In the first 100 patients of the Hannover group (65 males, mean age $58.7 \pm 13.6$ years) as of October 2014 [49], surgical indication was dissection in 57 (38 acute) and aneurysm in 43; there were 11 Marfan patients, 28 redo operations, 40 root procedures, and 12 coronary artery bypasses. The times of cardiopulmonary bypass, cross-clamp, circulatory arrest, and antegrade cerebral perfusion were $241 \pm 61$, $123 \pm 62,57 \pm 35$ [49], and $85 \pm 39$ minutes [25], respectively. Early mortality was $6 \%$. The rates of stroke, re-exploration for bleeding, and spinal cord injury were $10 \%, 13 \%$ [49], and 6\% [25], respectively. In follow-up, 19 secondary interventions on the downstream aorta were required (7 open, 12 endovascular) [49]. At 1 year, two late deaths occurred; survival was $77 \pm 7 \%$ and freedom from distal operation was $73 \pm 8 \%$ [25]. The Munich group implanted the Thoraflex in 38 patients as of September 2014, including 12 acute Type A (32\%), 2 acute Type B $(6 \%)$, and 14 chronic dissections (36\%), and 10 aneurysms (26\%). Mean age was $62 \pm 12$ years, and
24 patients (63\%) were male. In-hospital mortality was $18 \%$ (7/38). Early morbidities included stroke in 2 cases $(5 \%)$, phrenic nerve injury in $5(13 \%)$ and permanent dialysis in 2 (5\%). No spinal cord injury occurred. Late death occurred in one case $(2.6 \%)$ and a downstream procedure was required in five (13\%) [50]. In the Bologna experience with 11 patients (9 with chronic dissection and 2 aneurysms, age $63 \pm 9$ years), the time of cardiopulmonary bypass and antegrade cerebral perfusion was $227 \pm 98$ and $81 \pm 29$ minutes, respectively; no cases of early death, spinal cord injury, or stroke occurred. Early morbidities included reexploration for bleeding in 2 cases, transient ischemic attack in 1, and renal failure requiring temporary dialysis in 1 [51]. Currently Thoraflex Hybrid is not commercially available in the United States.

\section{Cronus}

The Cronus open stented graft (MircoPort, Shanghai, China) was designed and introduced by Dr. Sun in 2003 [52]. It consists of a regular Dacron vascular tube and interconnected Z-shaped stents made from conichrome (a Co-Cr-Ni-Mo-Fe alloy). At the proximal and distal ends, there is an extra centimeter of Dacron sewing cuff, to which a conventional hand-sewn anastomosis can be performed (Figure 8). The graft is $4-15 \mathrm{~cm}$ in length and $21-32 \mathrm{~mm}$ in diameter. Compared with other devices, the Cronus is more compact (15-25 cm in full length) due to the avoidance of the unstented portion, which allows for more accurate deployment deep into the operative field of the descending aorta.

The delivery system consists of a grip handle, a pull wire and a fixation string of 2-0 silk, which holds the prosthesis in a compressed state before deployment. The graft is bent slightly to conform to the arch curvature and inserted into the proximal descending aorta. Deployment simply involves gripping the handle in one hand and pulling out the pull wire with the other hand; the stent graft expands automatically, usually within seconds (see supplemental Video 3 at http:// dx.doi.org/10.12945/j.aorta.2015.14.062.vid.03) [53]. Distal anastomosis is located between the left carotid and left subclavian arteries and sutured using continuous stitches of 3-0 or 4-0 polypropylene. The arch 


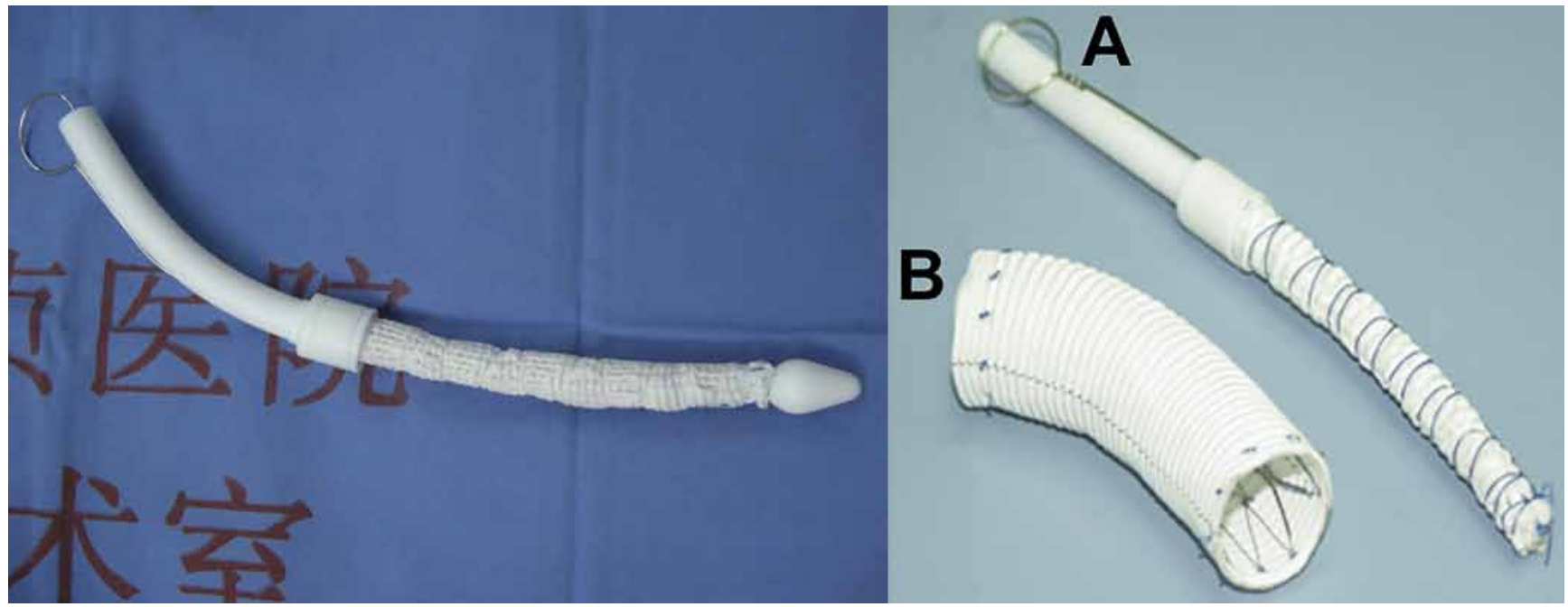

Figure 8. The Cronus open stented graft and its delivery system (Reprinted with permission from Elsevier. Left: Ref [69]; Right: Sun et al. Surgery for Marfan patients with acute Type A dissection using a stented elephant trunk procedure. Ann Thorac Surg. 2008;86:1821-5).

vessels are reconnected end-to-end to the branches of a separate, four-branched graft (Figure 9). To
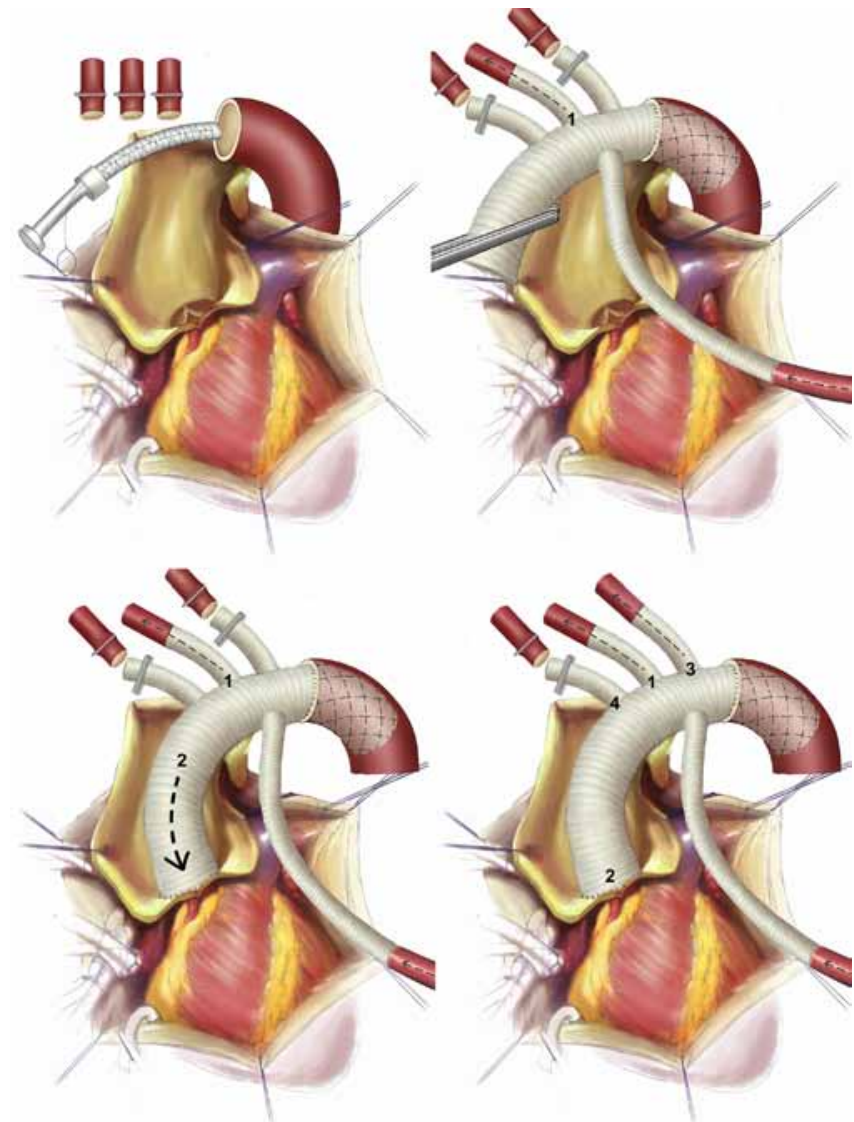

Figure 9. Deployment of Cronus and arch reconstruction (Reprinted with permission from Ma WG, et al. Aorta (Stamford) 2013;1:59-64. [54]). minimize the time of cerebral and cardiac ischemia, the left common carotid artery is reconstructed first, then the proximal ascending aorta, followed by the left subclavian and innominate arteries $[54,55]$.

Owing to its technical simplicity, over 18,000 patients have been treated successfully with the Cronus in China and South American countries [56,57]. In a group of 803 patients with Type A dissection (age $46 \pm 11$ years), the times of cardiopulmonary bypass, selective antegrade cerebral perfusion, and cross-clamp were $193 \pm$ $51,24 \pm 8$, and $106 \pm 40$ minutes, respectively. Operative mortality was $6.5 \%(52 / 803)$ and the incidences of stroke and spinal cord injury were 2.0\% (16/803) and $2.3 \%$ (19/803), respectively [17]. In another cohort of 291 patients with Type A dissection followed up for $42 \pm 18$ months, the overall late mortality was $3.5 \%$ $(10 / 291)$, obliteration of the false lumen around the stented graft occurred in $90.8 \%$ (256/282), and reintervention was required in 1.7\% (5/291) of patients [58]. In a series of 104 dissection patients with an arch entry tear (excluding retrograde dissections arising from the descending aorta), the operative mortality was $8.6 \%$ (9/104). Early morbidity included renal failure in 4 cases $(3.8 \%)$, spinal cord injury in three $(2.9 \%)$, stroke in $2(1.9 \%)$, limb ischemia in $2(1.9 \%)$, reexploration for bleeding in $2(1.9 \%)$, and recurrent laryngeal nerve injury in $1(1.0 \%)$. Follow-up was complete in $100 \%$ for $5.0 \pm 2.6$ years (range 1.3-11.1). Late death occurred in 2 patients (1.9\%). Survival was $88.9 \%$ and no late distal reintervention was required at 10 years [59]. 

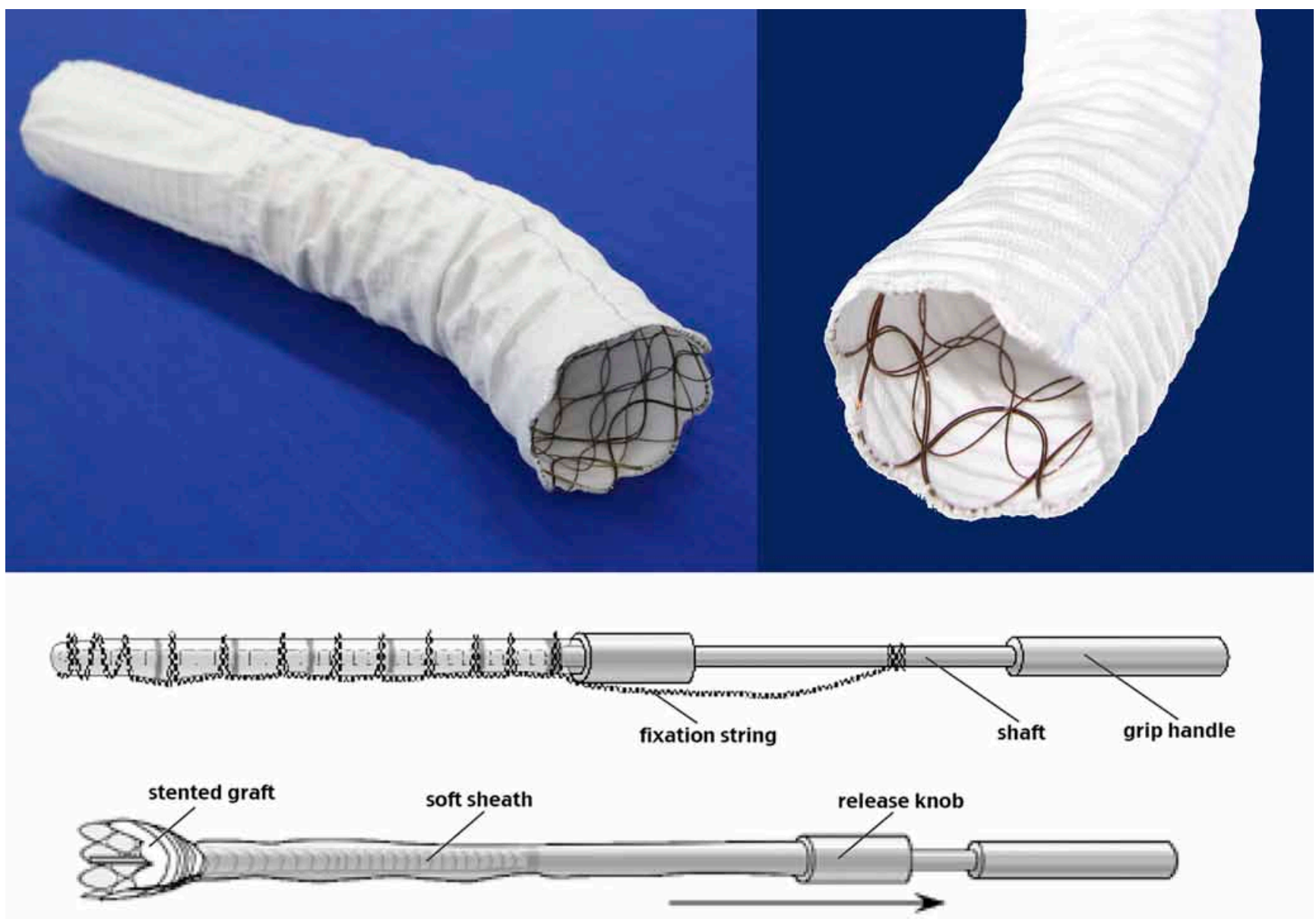

Figure 10. The J Graft open stent graft and its delivery system (Courtesy of Mr. Makoto Takakura and Mr. Hideki Kataoka from Japan Lifeline, adapted with permission).

\section{J Graft Open Stent Graft}

The J Graft open stent graft (Japan Lifeline, Tokyo, Japan) is an updated version of Dr. Kato's previous design $[8,60]$. It consists of a distal stented part that is made of a polyester tube with oval shaped nitinol stents, and a proximal unstented graft. The two parts are folded and mounted on a shaft within a soft sheath. J Graft is 21-39 $\mathrm{mm}$ in diameter and the stented portion is $6-12 \mathrm{~cm}$ in length (Figure 10). The full length of J Graft OSG is $57 \mathrm{~cm}$. Compared with other open stent grafts, one major advantage of the J Graft lies in its unique interconnected double-layered oval-shaped nitinol stents that allow for sliding between two the two layers, which may represent the best design for conforming to the curvature of the aorta [61].
The delivery system consists of a $15-\mathrm{cm}$ long grip handle integrated with a shaft, a 2-layer soft sheath attached to a release knob and a fixation string (Figure 10). Before deployment, the stented portion is bent to conform to the curvature of the aorta. In deployment, holding the grip handle in position and pulling back the release knob along with the sheath will release the whole prosthesis (Figure 11) (see supplemental Video 4 at http:// dx.doi.org/10.12945/j.aorta.2015.14.062.vid.04). For distal anastomosis, four 4-0 polypropylene stay sutures are placed first, followed by running stiches of 4-0 polypropylene reinforced by a felt strip [62]. The arch vessels are reconstructed with a separate branched graft in an end-to-end fashion $[61,63]$. 


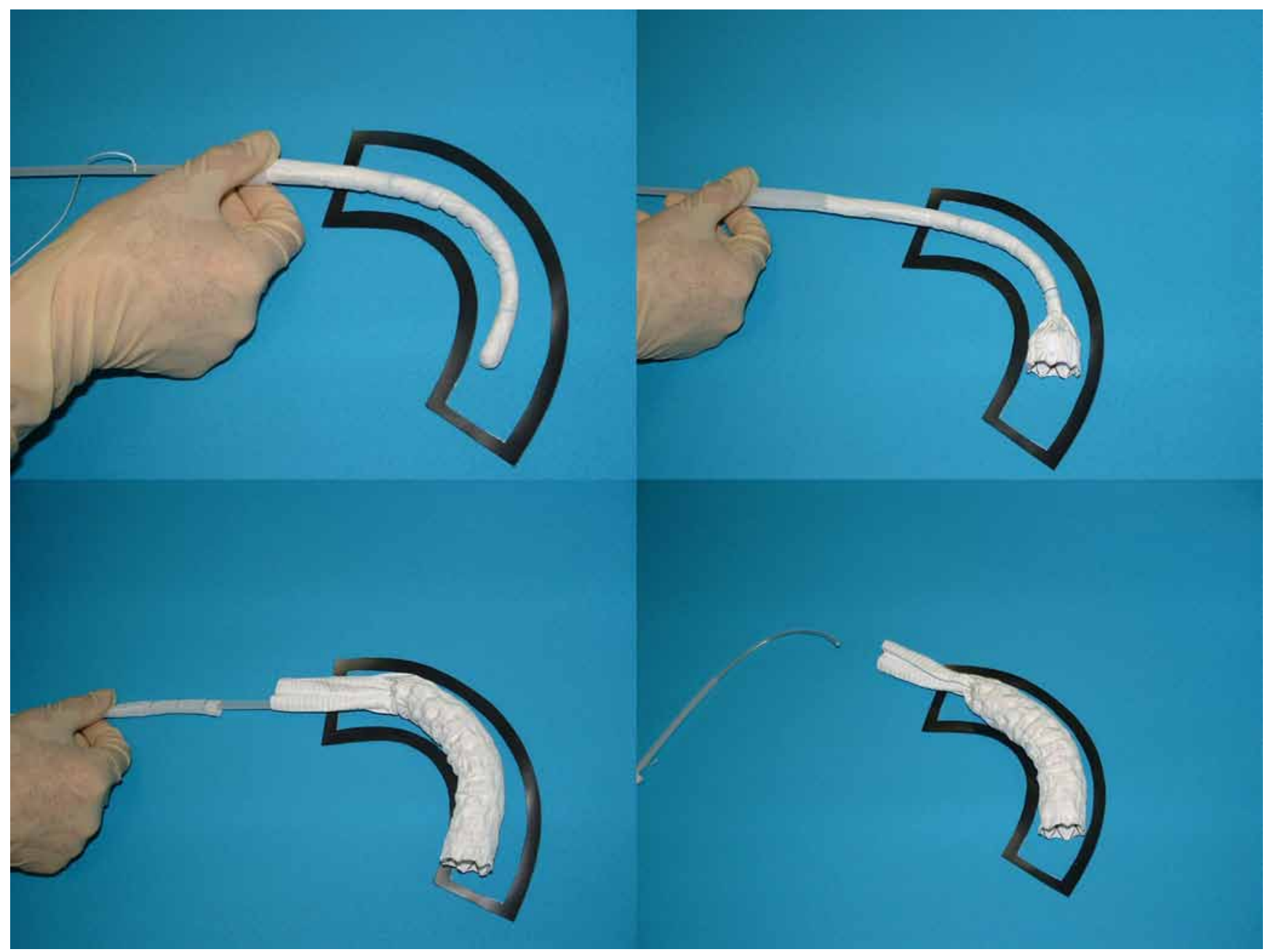

Figure 11. Deployment of J Graft open stent graft (Courtesy of Mr. Makoto Takakura and Mr. Hideki Kataoka from Japan Lifeline, adapted with permission).

During its premarketing clinical trial from March 2008 to September 2010, the J Graft OSG was implanted in 60 patients $[61,64]$. Mean age was $71.6 \pm$ 8.6 years and there were 44 males (73.3\%). Surgical indication was aneurysm in 38 (63\%) cases, acute Type A dissection in 6 (10\%), chronic Type A dissection in 2 (3\%), acute Type B in 1 (2\%), and chronic Type B in 13 (22\%). In-hospital mortality was 5\% (3/60) and early morbidities included stroke in $6(10 \%)$ cases, spinal cord injury in 4 (6.7\%), and endoleak in 2 (3.3\%). At 1 year, late mortality occurred in $10 \%(6 / 60)$ and secondary thoracic endovascular aortic repair was required in $8.3 \%$ (5/60), for distal aneurysmal dilation in 2 cases, thoracoabdominal aortic rupture in 1, and distal endoleak and downstream aneurysmal dilation in 2. Kaplan-Meier survival was $78 \%$ at 3.8 years
(1400 days). The J Graft OSG received commercial approval in Japan in February 2014 [65]. Between July 2014 and December 2015, J Graft was implanted in 2216 patients. Surgical indications were aneurysm in 51\%, Type A dissection in 33\%, Type B dissection in $10 \%$, aortic rupture in $3 \%$, type la endoleak after TEVAR in $2 \%$ and Kommerell diverticulum in $1 \%$. According to incomplete data, spinal cord injury occurred in $1.9 \%(43 / 2216)$, including paraparesis in 13 cases $(0.6 \%)$ and paraplegia in $30(1.3 \%)$. This incidence was much lower than the $6.7 \%$ reported in the premarket trial [61], which may be the result of avoidance of implanting below T8, and earlier distal perfusion after delivery of stent graft [Hideki Kataoka. Personal communication (email), January 2016]. 
Table 1. Comparison of currently available open stented grafts.

\begin{tabular}{|c|c|c|c|c|}
\hline Device & E-vita Open (Plus) & Thoraflex Hybrid & Cronus & J Graft Open \\
\hline Year of marketing & 2008 & 2012 & 2003 & 2014 \\
\hline Manufacturer & Jotec & Vascutek & MicroPort & Japan Lifeline \\
\hline $\begin{array}{l}\text { Number of implants } \\
\text { (by Dec 2015) }\end{array}$ & $>5000$ & $>1180$ & $>18000$ & $>2200$ \\
\hline Availability & Europe, Asia Pacific & $\begin{array}{l}\text { Europe, Asia Pacific, } \\
\text { Canada }\end{array}$ & China, South America & Japan \\
\hline \multicolumn{5}{|l|}{ Technical Aspects } \\
\hline Full length $(\mathrm{cm})$ & $18,22,23$ & 34,39 & $15-25$ & 57 \\
\hline Diameter of stent graft (mm) & $24-40$ & $28-40$ & $21-32$ & $21-39$ \\
\hline Length of stent graft (cm) & $13,15,16$ & 10,15 & $4-15$ & $6,9,12$ \\
\hline Proximal and distal diameter & Same & Different & Same & Same \\
\hline Stent design and material & Z shaped nitinol & Ring shaped nitinol & Z shaped conichrome & $\begin{array}{l}\text { Oval shaped 2-layer } \\
\text { nitinol }\end{array}$ \\
\hline Arch curvature & Fair & Better & Fair & Possibly best \\
\hline Sewing collar & Yes & Yes & No & No \\
\hline Distal sewing cuff & No & No & $1 \mathrm{~cm}$ & No \\
\hline Unstented portion & Yes & Yes & No & Yes \\
\hline Arch and perfusion branches & No & Yes & No & No \\
\hline Delivery method & Squeeze and pull & Pull, press, pull & Pull & Pull \\
\hline Need for positioning & Yes & No & No & Yes \\
\hline Guidewire or X-Ray & Necessary & Optional & No need & No need \\
\hline Blood permeability & $60 \mathrm{~mL} / \mathrm{cm}^{2} / \mathrm{min}$ & NA & NA & $150 \mathrm{~mL} / \mathrm{cm}^{2} / \mathrm{min}$ \\
\hline Method of arch repair & Carrel patch technique & $\begin{array}{l}\text { An integrated 4-branched } \\
\text { graft }\end{array}$ & $\begin{array}{l}\text { A separate 4-branched } \\
\text { graft }\end{array}$ & $\begin{array}{l}\text { A separate branched } \\
\text { graft }\end{array}$ \\
\hline Better indicated in & Aneurysm & Aneurysm and dissection & Dissection & Aneurysm \\
\hline \multicolumn{5}{|l|}{ Clinical Outcomes } \\
\hline Patient age (years) & 61 & $59 \pm 14$ & $46 \pm 11$ & $72 \pm 9$ \\
\hline $\begin{array}{l}\text { Cardiopulmonary bypass } \\
\text { time }\end{array}$ & 239 & $241 \pm 61$ & $193 \pm 51$ & $178 \pm 40$ \\
\hline $\begin{array}{l}\text { Selective antegrade cerebral } \\
\text { perfusion time }\end{array}$ & 71 & $85 \pm 39 *$ & $25 \pm 9$ & $40 \pm 37$ \\
\hline Early mortality (\%) & $15.8(90 / 568)$ & $8.7(13 / 149) \#$ & $6.4(53 / 832)$ & $5.0(3 / 60)$ \\
\hline Early stroke (\%) & $2.6(15 / 568)$ & $8.0(12 / 149) \#$ & $2.0(17 / 832)$ & $10.0(6 / 60)$ \\
\hline Early spinal cord injury (\%) & $3.5(20 / 568)$ & $4.0(6 / 149) \#$ & $2.4(20 / 832)$ & $6.7(4 / 60)$ \\
\hline Duration of follow-up (year) & 5 & $1 *$ & $5.0 \pm 2.6$ & 3.8 \\
\hline Late survival (\%) & $69-85$ & $77 \pm 7 *$ & 89 & 78 \\
\hline Late reintervention (\%) & $2-27$ & $14.1(24 / 149) \#$ & $6.5(69 / 1063)$ & $8.3(5 / 60,1 \mathrm{yr})$ \\
\hline
\end{tabular}

\# Calculated based on the reports of lus, Pichlmaier, Shrestha and Di Marco [25, 49-51]

* lus, et al. [25]

$\mathrm{NA}=$ not available. 


\section{Comments}

From a technical perspective, each of the aforementioned OSGs has its pros and cons (Table 1). For instance, although the Thoraflex and E-vita Open Plus are more sophisticated in design and intended for treating more complex arch and descending pathologies by using a single piece device, their deployment is time consuming and more technically demanding. The stented portion of Thoraflex is not available in sizes of less than $28 \mathrm{~mm}$, which may result in new intimal tears distal to the stent graft, hampering false lumen exclusion and thrombosis in cases of aortic dissections with small or narrowed true lumens [47]. In contrast, the Cronus and J Graft Open are more compact and easier to deploy (no fluoroscopy or guide wires for Cronus), but the Cronus requires a separate proximal graft and is not available in sizes of more than $32 \mathrm{~mm}$ for patients with larger aortas. It is important to note that, due to variability in patient and aortic characteristics, the technical merits of each device are difficult to quantify and directly comparing them is even more difficult. An ideal OSG should be capable of successfully treating patients in clinical settings ranging from dissection and aneurysm to associated pathologies like Kommerell diverticulum and coarctation $[66,67]$. In addition, an ideal graft should be able to provide satisfactory early and late outcomes for any patient, regardless of etiology [68], anatomy, acuity [48], and patient size, with minimal surgical risks, especially in terms of spinal cord injury, stroke, and endoleak. The "ideal" OSG would also include the following characteristics:

1. Ease of deployment (and expansion), without increasing technical complexity and prolonging ischemic and perfusion durations

2. Avoidance of fluoroscopy and guide wires

3. Firm fixation to the aortic wall without potential for graft migration

4. High flexibility and conformation to the curvature of the aorta, without kinking or twisting

5. Biocompatible surface with minimal blood permeability

6. Tapered distal end to fit well within the descending aorta, especially for patients with chronic dissection
7. Ease of anastomosis in secondary distal interventions, if such are necessary

With the evolution and expanded indications for the FET technique $[22,67,69,70]$, there is a growing need for versatile, technically simple, and highly durable systems involving less complicated deployment mechanisms which enable use in various indications. Because the currently available OSGs have not yet obtained FDA approval in the United States, several modified FET techniques using endovascular stent grafts have been proposed as a "bailout" [71-73].

While none of the available OSGs can yet claim to be an ideal device, technology continues to improve towards this goal.

As novel devices and systems are being developed specifically for the FET technique $[74,75]$ and manufacturers are frequently improving their technology to update their devices, more widespread use can be expected. For example, the 3 zone aortic arch hybrid prosthesis recently designed by Jakob, E-Novia, combines a routine proximal ascending polyester graft in continuity with an uncovered, nitinol stent in the arch portion and a stented graft in the descending aorta [76]. It is aimed at single-stage repair of ascending, arch and descending pathology and preliminary results have been favorable in patients with very high surgical risks [77]. Reports have emerged on the use of branched OSGs with one to three self-expanding stented side branches in an attempt to facilitate distal anastomosis and arch reconstruction [78, 79]. Favorable long-term outcomes have also been achieved with the Matsui-Kitamura stent graft [80].

Continued technologic improvements in FET technology can fairly be expected to result in improved clinical outcomes and quality of life for patients with complex aortic diseases.

\section{Acknowledgements}

This study was supported in part by the National Key Technologies R\&D Program (Grant 2015BA112B03) and Special Research Fund for Public Health and Welfare (Grant 201402009). The authors wish to express their sincere gratitude to Dr. Maximilian A. Pichlmaier from Universität München, Germany for his generous and invaluable help in making edits and comments and providing figures for this paper. We are also grateful 
for Profs. Heinz G. Jakob from Universitätsklinikum Essen - Westdeutsches Herzzentrum and Malakh L. Shrestha from Medizinischen Hochschule Hannover, Germany; Mr. John McKenna and Mr. Jonathon Hargreaves from Vascutek Terumo Cardiovascular Systems, Mr. Makoto Takakura and Mr. Hideki Kataoka from Japan Lifeline Co., Ltd, and Ms. Grace Li from the AME Publishing Company, who gave permission to use and adapt the data, videos, and figures that they have provided.

\section{Conflict of Interest}

Dr. Elefteriades is an investigator for the clinical trial of Thoraflex Hybrid in US. The other authors have no conflicts of interest relevant to this publication.

\section{Comment on this Article or Ask a Question}

\section{References}

1. Borst HG, Walterbusch G, Schaps D. Extensive aortic replacement using "elephant trunk" prosthesis. Thorac Cardiovasc Surg. 1983;31:37-40. DOI: 10.1055/s-20071020290

2. Etz $C D$, Plestis KA, Kari FA, Luehr $M$, Bodian CA, Spielvogel D, et al. Staged repair of thoracic and thoracoabdominal aortic aneurysms using the elephant trunk technique: a consecutive series of 215 first stage and 120 complete repairs. Eur J Cardiothorac Surg. 2008;34:605-615. DOI: 10.1016/j.ejcts.2008.04.045

3. Shrestha M, Martens A, Kruger H, Maeding I, lus F, Fleissner F, et al. Total aortic arch replacement with the elephant trunk technique: Single-centre 30-year results. Eur J Cardiothorac Surg. 2014;45:289-296. DOI: 10.1093/ejcts/ezt359

4. Estrera AL, Miller CC, 3rd, Porat EE, Huynh TT, Winnerkvist A, Safi HJ. Staged repair of extensive aortic aneurysms. Ann Thorac Surg. 2002;74:S1803-1805. DOI: 10.1016/ S0003-4975(02)04151-6

5. Rokkas CK, Kouchoukos NT. Single-stage extensive replacement of the thoracic aorta: The arch-first technique. J Thorac Cardiovasc Surg. 1999;117:99-105. DOI: 10.1016/S0022-5223(99)70473-3

6. Massimo CG, Presenti LF, Favi PP, Crisci C, Cruz Guadron EA. Simultaneous total aortic replacement from valve to bifurcation: Experience with 21 cases. Ann Thorac Surg. 1993;56:1110-1116. DOI: 10.1016/00034975(95)90026-8

7. Parodi JC, Palmaz JC, Barone HD. Transfemoral intraluminal graft implantation for abdominal aortic aneurysms. Ann Vasc Surg. 1991;5:491-499. DOI: 10.1007/BF02015271

8. Kato M, Ohnishi K, Kaneko M, Ueda T, Kishi D, Mizushima T, et al. New graft-implanting method for thoracic aortic aneurysm or dissection with a stented graft. Circulation. 1996;94:II188-193. PMID: 8901744

9. Kato M, Ohnishi K, Kaneko M, Imagawa $\mathrm{H}$, Ueda T, Kuratani T, et al. Development of an expandable intra-aortic prosthesis for experimental aortic dissection. ASAIO J. 1993;39:M758-761. DOI: 10.1097/00002480-199339030-00117

10. Kato M, Matsuda T, Kotoh K, Kaneko M, Imagawa $H$, Ueda $T$, et al. Development of a chronic endothelialized transcatheter implantable intra-aortic graft. ASAIO J. 1993;39:M518-521. DOI: 10.1097/00002480-199339030-00066

11. Kato $M$, Matsuda $T$, Kaneko $M$, Ueda $T$, Kuratani T, Yoshioka $Y$, et al. Experimental assessment of newly devised transcatheter stent-graft for aortic dissection. Ann Thorac Surg. 1995;59:908-915. DOI: 10.1016/0003-4975(94)00958-A

12. Karck $M$, Chavan A, Hagl C, Friedrich $H$, Galanski $M$, Haverich A. The frozen elephant trunk technique: A new treatment for thoracic aortic aneurysms. J Thorac Cardiovasc Surg. 2003;125:1550-1553. DOI: 10.1016/S0022-5223(03)00045-X

13. Suto $Y$, Yasuda K, Shiiya N, Murashita $T$, Kawasaki M, Imamura M, et al. Stented elephant trunk procedure for an extensive aneurysm involving distal aortic arch and descending aorta. J Thorac Cardiovasc Surg. 1996;112:1389-1390. DOI: 10.1016/ S0022-5223(96)70157-5

14. Palma JH, Almeida DR, Carvalho AC, Andrade JC, Buffolo E. Surgical treatment of acute Type $B$ aortic dissection using an endoprosthesis (elephant trunk). Ann Thorac Surg. 1997;63:1081-1084. DOI: 10.1016/ S0003-4975(97)00052-0

15. Orihashi K, Sueda T, Watari M, Okada K, Ishii O, Matsuura Y. Endovascular stent-grafting via the aortic arch for distal aortic arch aneurysm: An alternative to endovascular stent-grafting. Eur J Cardiothorac Surg. 2001;20:973978. DOI: 10.1016/S1010-7940(01)00909-5

16. Kato M, Matsuda T, Kaneko M, Kuratani T, Mizushima T, Seo Y, et al. Outcomes of stent-graft treatment of false lumen in aortic dissection. Circulation. 1998;98:II305312. PMID: 9852919
17. Ma WG, Zheng J, Zhang W, Sun K, Ziganshin BA, Wang LF, et al. Frozen elephant trunk with total arch replacement for Type A aortic dissections: Does acuity affect operative mortality? J Thorac Cardiovasc Surg. 2014;148:963-972. DOI: 10.1016/j. jtcvs.2014.06.005

18. Uchida N, Katayama A, Tamura K, Sutoh M, Kuraoka M, Murao N, et al. Long-term results of the frozen elephant trunk technique for extended aortic arch disease. Eur J Cardiothorac Surg. 2010;37: 1338-1345. DOI: 10.1016/j.ejcts.2010.01 .007

19. Uchida N, Katayama A, Tamura K, Sutoh M, Kuraoka M, Ishihara H. Frozen elephant trunk technique and partial remodeling for acute Type A aortic dissection. Eur J Cardiothorac Surg. 2011;40:1066-1071. DOI: 10.1016/j.ejcts.2011.02.074

20. Uchida N. Open stent grafting for complex diseases of the thoracic aorta: Clinical utility. Gen Thorac Cardiovasc Surg. 2013;61:118-126. DOI: 10.1007/s11748012-0151-y

21. Katayama A, Uchida N, Katayama K, Arakawa M, Sueda T. The frozen elephant trunk technique for acute Type A aortic dissection: Results from 15 years of experience. Eur J Cardiothorac Surg. 2015;47:355-360. DOI: 10.1093/ejcts/ezu173

22. Shrestha M, Bachet J, Bavaria J, Carrel TP, De Paulis R, Di Bartolomeo R, et al. Current status and recommendations for use of the frozen elephant trunk technique: a position paper by the Vascular Domain of EACTS. Eur J Cardiothorac Surg. 2015;47:759-769. DOI: 10.1093/ejcts/ ezv085

23. Weiss G, Santer D, Dumfarth J, Pisarik $H_{\text {, }}$ Harrer ML, Folkmann S, et al. Evaluation of the downstream aorta after frozen elephant trunk repair for aortic dissections in terms of diameter and false lumen status. Eur J Cardiothorac Surg. 2016;49:118-124. DOI: $10.1093 /$ ejcts/ezv044 
24. Takagi H, Umemoto T. A meta-analysis of total arch replacement with frozen elephant trunk in acute Type A aortic dissection. Vasc Endovascular Surg. 2016; 50: 33-46. DOI: 10.1177/1538574415624767

25. lus $F$, Fleissner $F$, Pichlmaier $M$, Karck $M$, Martens A, Haverich A, et al. Total aortic arch replacement with the frozen elephant trunk technique: 10-year follow-up single-centre experience. Eur J Cardiothorac Surg. 2013;44:949-957. DOI: 10.1093/ ejcts/ezt229

26. Shrestha M, Beckmann E, Krueger $H$, Fleissner F, Kaufeld T, Koigeldiyev N, et al. The elephant trunk is freezing: The Hannover experience. J Thorac Cardiovasc Surg. 2015;149:1286-1293. DOI: 10.1016/j. jtcvs.2015.01.044

27. Karck $M$, Khaladj $N$. The new wave of elephant trunk technique. In: Rousseau $\mathrm{H}$, Verhoye J-P, Heautot J-F, eds. Thoracic Aortic Diseases: Springer Berlin Heidelberg; 2006, p. 125-131. DOI: 10.1007/3-54038309-3_11

28. Pichlmaier MA, Teebken OE, Baraki $\mathrm{H}$, Haverich A. The frozen elephant trunk technique. Multimed Man Cardiothorac Surg. 2007;2007:mmcts.2006.001990. DOI: 10.1510/mmcts.2006.001990

29. Karck M, Chavan A, Khaladj N, Friedrich H, Hagl C, Haverich A. The frozen elephant trunk technique for the treatment of extensive thoracic aortic aneurysms: Operative results and follow-up. Eur J Cardiothorac Surg. 2005;28:286-290. DOI: 10.1016/j. ejcts.2005.02.046

30. Baraki H, Hagl C, Khaladj N, Kallenbach K, Weidemann J, Haverich A, et al. The frozen elephant trunk technique for treatment of thoracic aortic aneurysms. Ann Thorac Surg. 2007;83:S819-831. DOI: 10.1016/j. athoracsur.2006.10.083

31. Chavan A, Karck M, Hagl C, Winterhalter M, Baus S, Galanski M, et al. Hybrid endograft for one-step treatment of multisegment disease of the thoracic aorta. J Vasc Interv Radiol. 2005;16:823-829. DOI: 10.1097/01. RVI.0000159205.00299.97

32. Jakob H, Tsagakis K, Leyh R, Buck T, Herold $U$. Development of an integrated stent graft-Dacron prosthesis for intended onestage repair in complex thoracic aortic disease. Herz. 2005;30:766-768. DOI: 10.1007/ s00059-005-2765-7

33. Tsagakis K, Pizanis N, Baba HA, Wendt $\mathrm{D}$, Wisbrun N, Altenbernd J, et al. Impermeability to blood of the E-vita open plus hybrid stent-graft: Experimental and clinical evaluation. J Endovasc Ther. 2010;17:340-348. DOI: 10.1583/092758MR. 1
34. Jotec ${ }^{\circledast} \mathrm{GmbH}$. $\mathrm{E}^{\oplus}$-vita Open Plus stent graft system. Available at http://www.jotec. com/en/products/thoracic-stent-grafts/e-vita-open-plus.html?file=files/media/ pdf/EN/Brochure\%20E-vita\%20OPEN\%20 PLUS\%20\%28EN\%29.pdf. Accessed July 31, 2014.

35. Jakob $\mathrm{H}$. Facilitated surgical strategy in total arch replacement and descending aorta stent grafting with the E-vita open hybrid prosthesis. Ann Cardiothorac Surg. 2013;2:663-664. DOI: 10.3978/j.issn.2225319X.2013.09.15

36. Jotec ${ }^{\oplus} \mathrm{GmbH}$. $\mathrm{E}^{\oplus}$-vita Open Plus: the endoluminal stentgraft system for open heart surgery. Available at http://www.jotec. com/en/products/thoracic-stent-grafts/evita-open-plus.html. Accessed December 31, 2015.

37. Oo A. The frozen elephant trunk: Indications, technique, and results. Available at http://www.ctsnet.org/article/ frozen-elephant-trunk-indications-technique-and-results. Accessed August 15, 2014.

38. Jakob H, Tsagakis K, Pacini D, Di Bartolomeo R, Mestres C, Mohr F, et al. The International E-vita Open Registry: data sets of 274 patients. J Cardiovasc Surg. (Torino) 2011;52:717-723. PMID: 21894139

39. Jakob H, Tsagakis K. International E-vita open registry. Ann Cardiothorac Surg. 2013;2:296-299. DOI: 10.3978/j.issn.2225319X.2013.03.10

40. Leontyev S, Tsagakis K, Pacini D, Di Bartolomeo R, Mohr FW, Weiss G, et al. Impact of clinical factors and surgical techniques on early outcome of patients treated with frozen elephant trunk technique by using EVITA open stent-graft: results of a multicentre study. Eur J Cardiothorac Surg. 2016;49:660666. DOI: $10.1093 /$ ejcts/ezv150

41. Pacini D. Insights from the E-vita Open Registry. Second Aortic Live Symposium. Essen, Germany; September 11-13, 2014.

42. Shrestha M, Pichlmaier M, Martens A, Hagl C, Khaladj N, Haverich A. Total aortic arch replacement with a novel four-branched frozen elephant trunk graft: First-in-man results. Eur J Cardiothorac Surg. 2013;43:406410. DOI: $10.1093 /$ ejcts/ezs296

43. Donas KP, Rancic Z, Lachat M, Pfammatter T, Frauenfelder T, Veith FJ, et al. Novel sutureless telescoping anastomosis revascularization technique of supra-aortic vessels to simplify combined open endovascular procedures in the treatment of aortic arch pathologies. J Vasc Surg. 2010;51:836-841. DOI: 10.1016/j.jvs.2009.09.054

44. Ruggieri VG, Vola M, Anselmi A, Verhoye JP. Multibranched hybrid device for frozen elephant trunk: What does it change? J Thorac Cardiovasc Surg. 2015;150:253-255. DOI: 10.1016/j.jtcvs.2015.03.018

45. Di Eusanio M, Schepens MA, Morshuis WJ, Dossche KM, Kazui T, Ohkura K, et al. Separate grafts or en bloc anastomosis for arch vessels reimplantation to the aortic arch. Ann Thorac Surg. 2004;77:2021-2028. DOI: 10.1016/j.athoracsur.2003.10.094

46. Urbanski PP, Irimie V, Zembala M. Non-anatomical implantation of supra-aortic branches for customizing the standard form of Thoraflex ${ }^{\mathrm{TM}}$ hybrid prosthesis to a patient's anatomical requirements. Interact Cardiovasc Thorac Surg. 2016;22:109111. DOI: $10.1093 /$ icvts/ivv285

47. Di Eusanio M. Editorial comment: Frozen elephant trunk surgery: Where do we go from here? Eur J Cardiothorac Surg. 2013;44:1083-1084. DOI: 10.1093/ejcts/ ezt191

48. Vallabhajosyula $P$, Szeto WY. Fourbranched graft with stent hybrid prosthesis for single-stage treatment of chronic aortic arch pathology J Thorac Cardiovasc Surg. 2015;150:255-7. DOI: 10.1016/j.jtcvs.2015.04.023

49. Shrestha M, Krueger $H$, Kaufeld KM, Beckmann E, Koigeldiyev N, Fleissner F, et al. Total aortic arch replacement with the Thoraflex hybrid frozen elephant trunk prosthesis: report on the first 100 patients in a single center. AATS 95th Annual Meeting. Seattle, WA; April 25-29, 2015. Available at: http://aats.org/annualmeeting/ program-books/2015/77.cgi. Accessed March 31, 2015

50. Pichlmaier MA. Thoraflex hybrid graft - the Munich experience. Second Aortic Live Symposium. Essen, Germany; September 11-13, 2014.

51. Di Marco L, Pacini D, Leone A, Pantaleo A, Cefarelli M, Di Eusanio M, et al. The Thoraflex hybrid frozen elephant trunk device: the Bologna experience. Ital J Vasc Endovasc Surg. 2014;21:117-123.

52. Liu ZG, Sun LZ, Chang Q, Zhu JM, Dong C, $\mathrm{Yu} C \mathrm{CT}$, et al. Should the "elephant trunk" be skeletonized? Total arch replacement combined with stented elephant trunk implantation for Stanford Type A aortic dissection. J Thorac Cardiovasc Surg. 2006;131:107113. DOI: 10.1016/j.jtcvs.2005.09.015

53. Sun LZ, Ma WG, Zhu JM, Zheng J, Liu YM, Ziganshin BA, et al. Sun's procedure for chronic Type A aortic dissection: total arch replacement using a tetrafurcate graft with stented elephant trunk implantation. Ann Cardiothorac Surg. 2013;2:665-666. DOI: 10.3978/j.issn.2225$319 \times .2013 .09 .20$ 
54. Ma WG, Zheng J, Liu YM, Zhu JM, Sun LZ. Dr. Sun's procedure for Type A aortic dissection: total arch replacement using tetrafurcate graft with stented elephant trunk implantation. Aorta (Stamford). 2013;1:59-64. DOI: 10.12945/j.aorta.2013.13.015.

55. Ma WG, Zhu JM, Zheng J, Liu YM, Ziganshin BA, Elefteriades JA, et al. Sun's procedure for complex aortic arch repair: Total arch replacement using a tetrafurcate graft with stented elephant trunk implantation. Ann Cardiothorac Surg. 2013;2:642-648. DOI: 10.3978/j.issn.2225-319X.2013.09.03

56. Wu HB, Zhang H, Wang ZW, Hu R, Li LC, Zhang $M$, et al. Surgery for acute aortic dissection using the Chinese CRONUS stented elephant trunk technique: Experience with 252 patients. J Thorac Cardiovasc Surg. 2014;148:2132-2138. DOI: 10.1016/j. jtcvs.2013.12.007

57. MicroPort Scientific Co. MicroPort Cronus $^{\mathrm{TM}}$ surgical stent graft system received re-registration. Available at http://www. microport.com.cn/en/media.php?curr_ page $=$ news_details\&id=208. Accessed December 18, 2014.

58. Sun LZ, Qi R, Zhu JM, Liu YM, Zheng J. Total arch replacement combined with stented elephant trunk implantation: a new "standard" therapy for Type a dissection involving repair of the aortic arch? Circulation. 2011;123:971-978. DOI: 10.1161/CIRCULATIONAHA.110.015081

59. Ma WG, Zhang W, Wang LF, Zheng J, Ziganshin BA, Charilaou P, et al. Aortic dissection with arch entry tear: Surgical experience in 104 patients during a 12-year period. JThorac Cardiovasc Surg. 2015 Dec 13. [Epub ahead of print]. DOI: 10.1016/j.jtcvs.2015.11.056

60. Kato M, Kuratani T, Kaneko M, Kyo $S$, Ohnishi K. The results of total arch graft implantation with open stent-graft placement for Type A aortic dissection. J Thorac Cardiovasc Surg. 2002;124:531-540. DOI: $10.1067 /$ mtc.2002.124388

61. Uchida N, Katayama A, Higashiue S, Shiono M, Hata M, Minami K, et al. A new device as an open stent graft for extended aortic repair: a multicentre early experience in Japan. Eur J Cardiothorac Surg. 2015 Sep 18. [Epub ahead of print]. DOI: 10.1093/ejcts/ezv310

62. Mukai S, Obata S, Morimoto H, Uchida N. An alternative method for reconstructing the distal aortic arch through median sternotomy via the pleural window. Interact Cardiovasc Thorac Surg. 2012;14:526-528. DOI: 10.1093/icvts/ivs013
63. Hata M, Akiyama K, Orime Y, Wakui S, Nakamura $T$, Shiono M. Less invasive quick open stenting using a J graft open stent for distal arch aneurysms. Thorac Cardiovasc Surg. 2015 Mar 18. [Epub ahead of print]. DOI: $10.1055 / \mathrm{s}-0035-1546299$

64. Japan Lifeline Co. J Graft open stent graft. Available at http://www.info.pmda. go.jp/ygo/pack/530381/22600BZX00033000_A_01_02/. Accessed January 10, 2015.

65. Japan Lifeline Co. Announcement of "J Graft Open stent-graft" get regulatory approval. Available at http://www.jll.co.jp/ news/detail.php? sid=28252ef6b7c6fcd1 . Accessed Febuary 11, 2014.

66. Idrees J, Arafat A, Svensson LG, Clair D, Roselli EE. Hybrid repair of aortic aneurysm in patients with previous coarctation. J Thorac Cardiovasc Surg. 2014;148:60-64. DOI: 10.1016/j.jtcvs.2013.03.045

67. Idrees J, Keshavamurthy S, Subramanian S, Clair DG, Svensson LG, Roselli EE. Hybrid repair of Kommerell diverticulum. J Thorac Cardiovasc Surg. 2014;147:973-976. DOI: 10.1016/j.jtcvs.2013.02.063

68. Roselli EE, Idrees JJ, Lowry AM, Masabni K, Soltesz EG, Johnston DR, et al. Beyond the aortic root: staged open and endovascular repair of arch and descending aorta in patients with connective tissue disorders. Ann Thorac Surg. 2016;101:906-912. DOI: 10.1016/j.athoracsur.2015.08.011

69. Li B, Pan XD, Ma WG, Zheng J, Liu YL, Zhu $J M$, et al. Stented elephant trunk technique for retrograde Type A aortic dissection after endovascular stent graft repair. Ann Thorac Surg. 2014;97:596-602. DOI: 10.1016/j.athoracsur.2013.09.033

70. Shrestha M, Fleissner F, lus F, Koigeldiyev N, Kaufeld T, Beckmann E, et al. Total aortic arch replacement with frozen elephant trunk in acute Type A aortic dissections: Are we pushing the limits too far? Eur J Cardiothorac Surg. 2015;47:361-366. DOI: 10.1093/ejcts/ezu185

71. Pochettino A, Brinkman WT, Moeller $P$, Szeto WY, Moser W, Cornelius K, et al. Antegrade thoracic stent grafting during repair of acute DeBakey I dissection prevents development of thoracoabdominal aortic aneurysms. Ann Thorac Surg. 2009;88:482490. DOI: 10.1016/j.athoracsur.2009.04.046

72. Roselli EE, Rafael A, Soltesz EG, Canale L, Lytle BW. Simplified frozen elephant trunk repair for acute DeBakey Type I dissection. J Thorac Cardiovasc Surg. 2013;145:S197201. DOI: 10.1016/j.jtcvs.2012.11.068
73. Reoma JL, Martin TD, Hess PJ, Jr., Beck AW. A novel technique for hybrid aortic arch reconstruction: The deployment cuff technique. Ann Thorac Surg. 2014;97:1464-1466. DOI: 10.1016/j.athoracsur.2013.08.067

74. Jakob H. Frozen elephant trunk in acute Type I dissection-A personal view. Ann Cardiothorac Surg. 2013;2:640-641. DOI: 10.3978/j.issn.2225-319X.2013.09.21

75. Shket AP, Ostrovsky YP, Shumavec VV, Zenkov AA, Spiridonov SV, Krutov VG, et al. Pilot clinical trial of Belarusian aortic stent graft system. Second Aortic Live Symposium. Essen, Germany; September 11-13, 2014.

76. Jakob H, Dohle DS, Tsagakis K. A new hybrid graft for fast ascending, arch and descending aortic replacement and endovascular stabilisation. In: Greenhalgh RM, editor. 35th International Charing Cross Symposium: Vascular and Endovascular Challenges Update. London, United Kingdom: BIBA Medical; 2013, p. 121-126.

77. Jakob H. Present and future: from the E-vita open gold standard to fast ascending, arch and descending repair with E-novia. Second Aortic Live Symposium. Essen, Germany; September 11-13, 2014.

78. Shimamura K, Kuratani T, Matsumiya G, Shirakawa $\mathrm{Y}$, Takeuchi $\mathrm{M}$, Takano $\mathrm{H}$, et al. Hybrid endovascular aortic arch repair using branched endoprosthesis: The second-generation "branched" open stent-grafting technique. J Thorac Cardiovasc Surg. 2009;138: 46-52. DOI: 10.1016/j.jtcvs.2009.03.025

79. Chen LW, Lu L, Dai XF, Wu XJ, Zhang GC, Yang GF, et al. Total arch repair with open triple-branched stent graft placement for acute Type A aortic dissection: Experience with 122 patients. J Thorac Cardiovasc Surg. 2014;148:521-528. DOI: 10.1016/j. jtcvs.2013.10.02

80. Midorikawa H, Kanno M, Takano T, Watanabe $\mathrm{K}$, Ueno K, Ono T, et al. Long-term results of open stent-grafting using a Matsui-Kitamura stent to treat thoracic aortic aneurysm. Ann Thorac Cardiovasc Surg. 2015;21:165-171. DOI: 10.5761/atcs.oa.14-00104

Cite this article as: Ma W-G, Zheng J, Sun L-Z, Elefteriades JA. Open Stented Grafts for Frozen Elephant Trunk Technique: Technical Aspects and Current Outcomes. AORTA (Stamford). 2015;3(4):122-135. DOI: http://dx.doi. org/10.12945/j.aorta.2015.14.062 